\title{
Coronary artery bypass grafting in a patient with situs inversus totalis and dextrocardia
}

\author{
Revascularização do miocárdio em paciente com situs inversus totalis e dextrocardia
}

Eduardo Keller SAADI ${ }^{1}$, Luis Henrique DUSSIN ${ }^{2}$, Alvaro NICOLAO ${ }^{3}$, Alcides José ZAGO ${ }^{4}$

RBCCV 44205-911

\begin{abstract}
Situs inversus totalis is a rare congenital anomaly. We report a case of a 78-year-old woman with this condition and ischemic coronary artery disease who underwent myocardial revascularization. The cardiac catheterism showed severe proximal stenosis with aneurysms in the anterior interventricular branch, diagonal artery, and right coronary artery. The procedure was done with the surgeon positioned in the left hand side of the patient, with the right internal thoracic artery anastomosed to the anterior interventricular branch, and to two more vein grafts. Very few cases have been reported in the world and this is the third case in Brazil, and the first in the world with coronary aneurysms.
\end{abstract}

Descriptors: Dextrocardia. Situs inversus. Coronary disease. Myocardial revascularization.

\footnotetext{
1. MD; Professor of School of Medicine and Cardiovascular Surgeon of UFRGS/Hospital de Clínicas de Porto Alegre

2. Cardiovascular Surgeon hired by Hospital de Clínicas de Porto Alegre; Master Degree in Surgery by UFRGS.

3. Cardiologist; Specialist by SBC.

4. Professor of Cardiology/UFRGS
}

Work performed at the Hospital de Clínicas de Porto Alegre, Porto Alegre, RS, Brazil

Correspondence address:

Eduardo Keller Saadi.

Rua Pedro Weingartner, 125/801

Porto Alegre, RS, Brasil - CEP: 90430-140.

E-mail: esaadi@terra.com.br

\section{Resumo}

O situs inversus totalis com dextrocardia é uma situação congênita rara. Relatamos o caso de uma paciente de 78 anos com esta anomalia, em síndrome coronariana aguda. A cinecoronariografia demonstrou lesões proximais graves, com aneurismas em artérias interventricular anterior, diagonal e coronária direita. Foram utilizados a artéria torácica interna direita anastomosada na artéria interventricular anterior e mais dois enxertos venosos. A paciente evoluiu bem. Poucos casos no mundo foram relatados com esta condição submetidos à cirurgia de revascularização do miocárdio, este é o terceiro caso no Brasil, sendo o primeiro no mundo com aneurismas coronarianos.

Descritores: Dextrocardia. Situs inversus. Coronariopatia. Revascularização miocárdica. 


\section{INTRODUCTION}

Situs inversus totalis is a rare congenital anomaly, in which by a defect in the rotation of the viscera in the embryonic stage, the visceral organs are reversed or mirrored from their normal positions, e.g., the liver developing on the left side, spleen of on the right side, among other changes. It is an autosomal recessive disease with an incidence of 1:10,000 [1-3].

\section{CASEREPORT}

A 78-year-old female patient diagnosed situs inversus totalis with dextrocardia. She was aware of the disease, since she was 13 years old. At the time, a surgery was proposed to "displace the heart to the right side". However, she chose not to undergo the surgical procedure. She has remained asymptomatic until few months ago when she developed angina of effort and heart failure. She has developed acute ischemic syndrome with positive deflection of the ST segment. She was referred to the Hospital das Clínicas de Porto Alegre. A chest x-ray confirmed dextrocardia (Figure 1); the echocardiogram showed, besides the dextrocardia, a systolic dysfunction of the left ventricle with an ejection fraction of $30 \%$; in relation to the aorta, the pulmonary artery was on the right and the aortic arch was right-sided. No other malformations were observed. The cardiac catheterism permitted the determination of two severe proximal lesions in the anterior interventricular branch with aneurysms (Figure 2) and severe lesions in both the right coronary artery (Figure 3) and the first diagonal artery. An angioplasty to place a stent was unsuccessfully attempted due to the aneurysms and the technical difficulties provided by the anatomy.

On May 15 2007, the patient underwent a coronary artery bypass grafting. After a median sternotomy was performed, we evaluated the anatomy: the apex of heart was on the right; the pulmonary artery was on the right in relation to the aorta; the right atrium was on the left side, and the left ventricle on the right. It was a mirror image of the normal heart (Figure 4). We chose to dissect the internal thoracic artery once the left one would not reach the anterior interventricular branch and would cross over the mediastinum. The right internal thoracic artery was dissected in the usual manner (pediculated) with the surgeon standing on the left side of the patient.

The extracorporeal circulation was established through cannulation of the ascending aorta and the right atrium at normothermia. The saphenous vein anastomosis was performed at first to the right coronary artery (in the right coronary sulcus), on the left side of the patient. Afterwards, the anastomosis of the saphenous vein graft to the first diagonal branch was performed followed by the

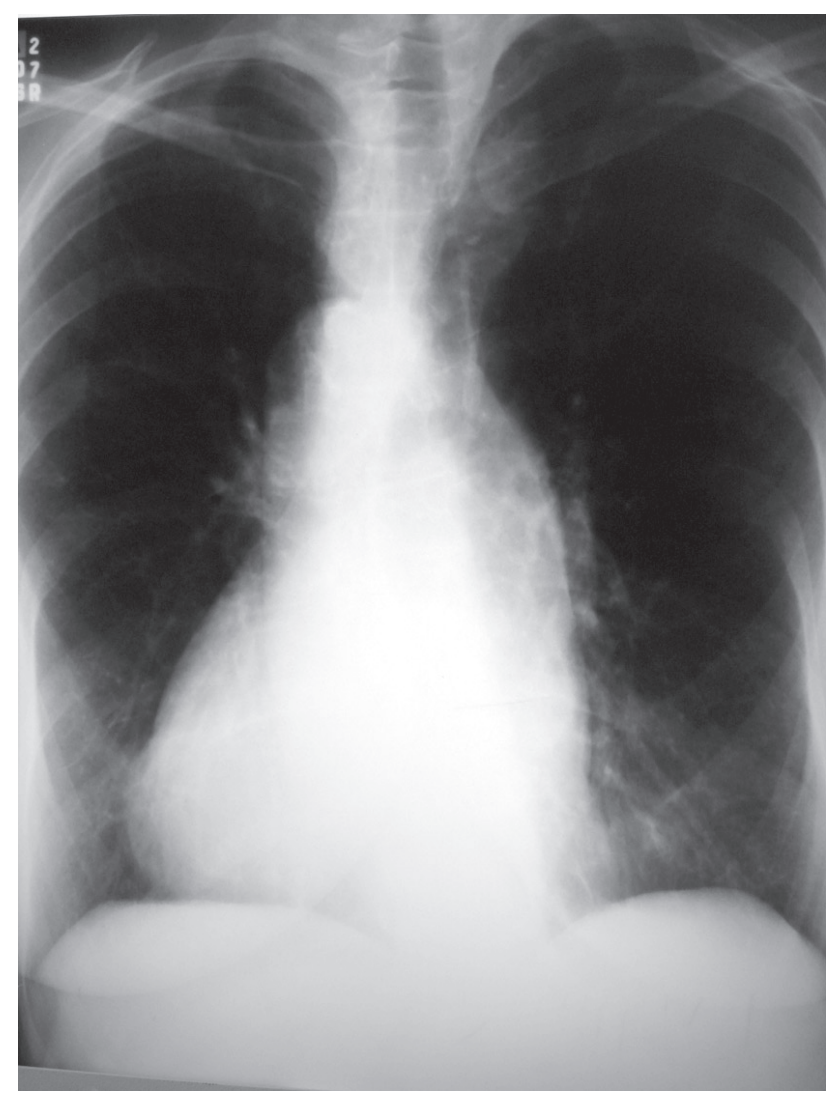

Fig. 1 - Posteroanterior radiograph of the chest showing dextrocardia

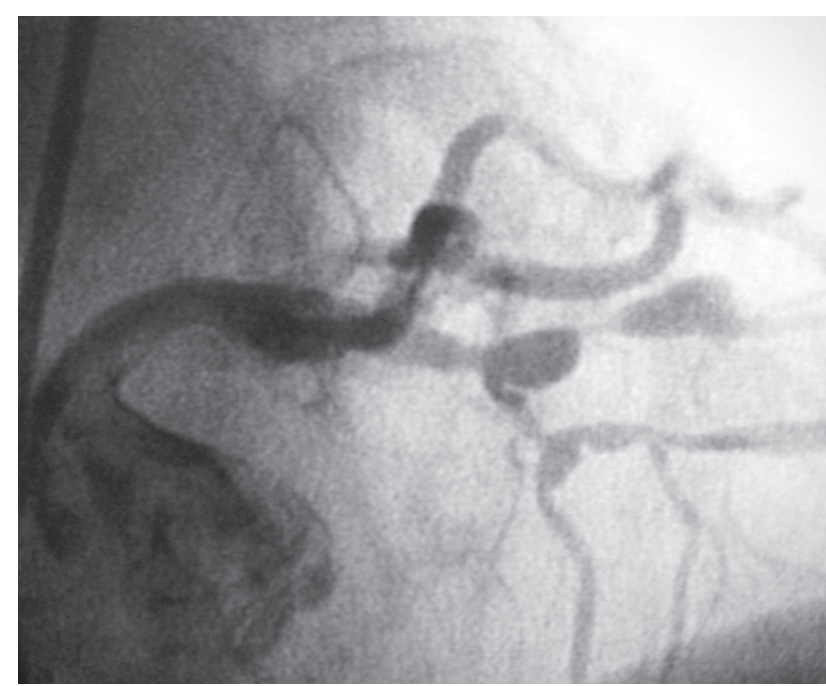

Fig. 2 - Cinecoronariography with the corrected image showing severe lesions with aneurysms in the anterior interventricular branch 


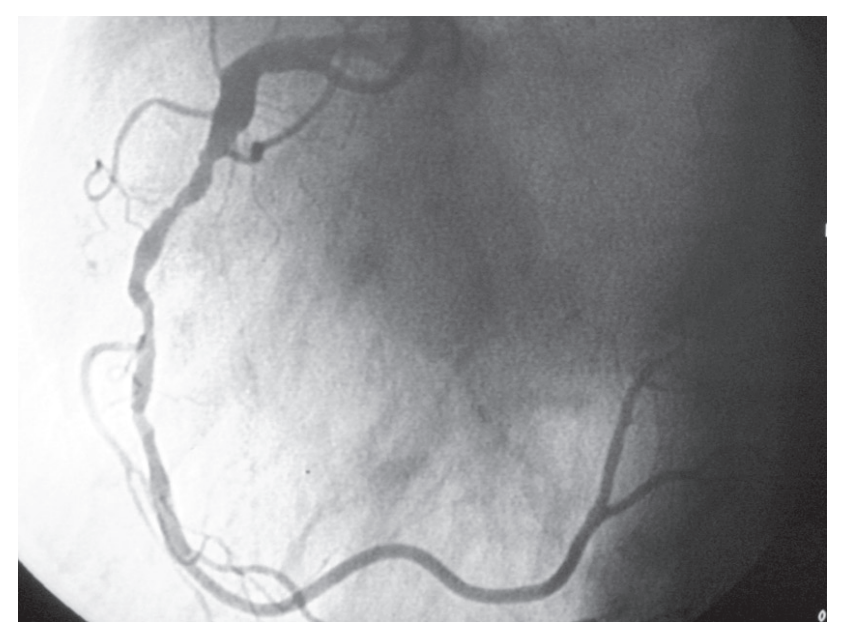

Fig. 3 - Cinecoronariography showing sequential lesions in the right coronary artery

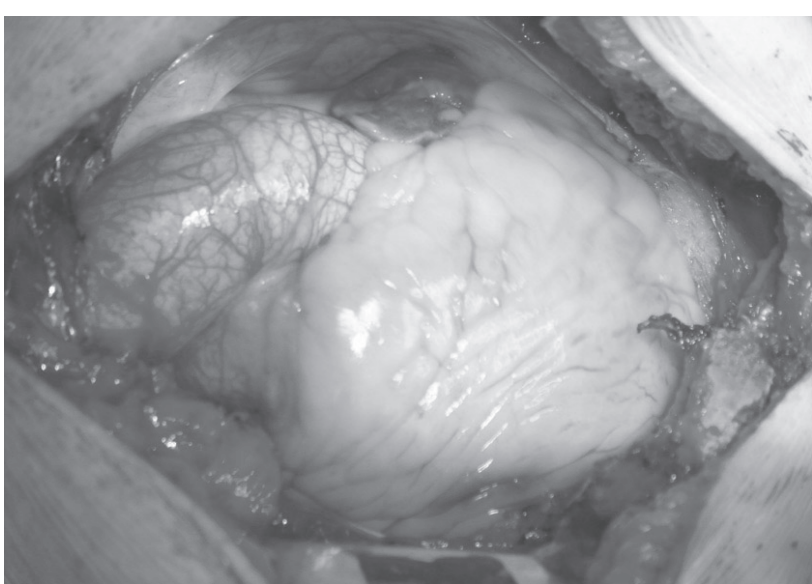

Fig. 4 - Heart anatomy seen from the right side of the patient: dextrocardia, aorta to the left and pulmonary artery to the right

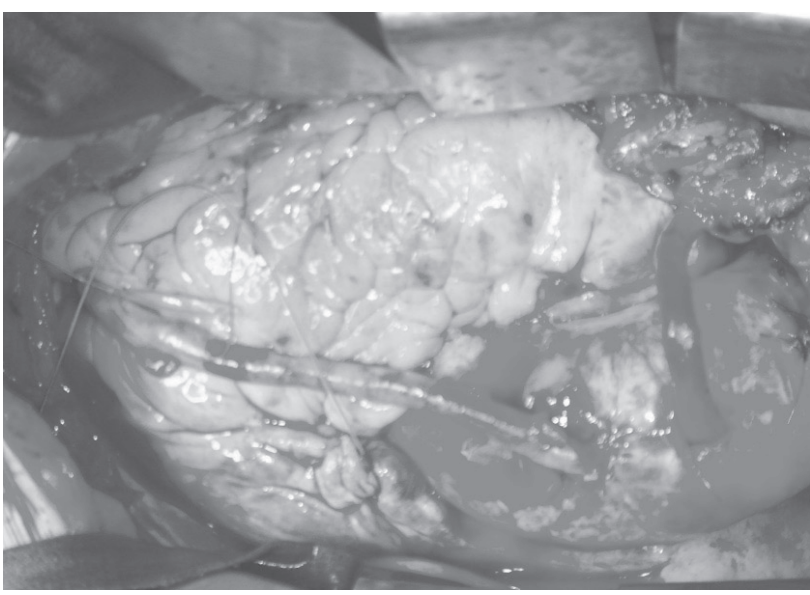

Fig. 5 - Myocardial revascularization with two coronary bypass grafting (right coronary artery and diagonal artery) and right internal thoracic artery to the anterior interventricular branch anastomosis of the right internal thoracic artery graft to the anterior interventricular branch. The two vein grafts were anastomosed to the aorta by partial clamping (Figure 5). The aneurysms were not manipulated. The patient had an uneventful postoperative course.

\section{DISCUSSION}

Situs inversus totalis with dextrocardia is a rare condition. It affects 1 in 10,000 people and the incidence of ischemic cardiopathy is presumed to be the same as that of the general population. It was first reported by Hieronymus Fabricius in 1606, but it only was well-described in 1926 [1$3]$. Less than 10 cases have been reported worldwide in patients who have undergone coronary artery bypass grafting with this condition. This is the third case in Brazil [4-6]. Less frequent is the use of the right internal thoracic artery. There are no cases reported in the worldwide literature about this condition associated with coronary aneurysms. An outstanding peculiarity in this condition and what makes the procedure much easier is the surgeon standing on the left side of the patient.

\section{REFERENCES}

1. Cleveland M. Situs inversus viscerum: anatomic study. Arch Surg. 1926;13:343.

2. Rosemberg NH, Rosemberg IN. Simultaneous association of situs inversus, coronary heart disease and hiatus hernia. Ann Int Med. 1949;30:851-9.

3. Torgersen J. Genetic factors in visceral asymmetry and in the development and pathologic changes of lungs, heart and abdominal organs. Arch Pathol. 1949;47:566-93.

4. Soncini da Rosa GR, Lemke VG, Madeira Neto J, Martins AAF, Kubrusly LF. Revascularização do miocárdio em paciente com situs inversus totalis: relato de caso. Rev Bras Cir Cardiovasc. 2002;17(4):359-61.

5. Abensur H, Ramires JA, Dallan LA, Jatene A. Right mammarycoronary anastomosis in a patient with situs inversus. Chest. 1988;94(4):886-7.

6. Pêgo-Fernandes PM, de Serro-Azul JB, Matheus F, Maehara BS. Revascularização do miocárdio em paciente com situs inversus totalis. Arq Bras Cardiol. 2007;88(5):e103-6. 